\title{
Comparison of distal forelimb conformations between Japanese Black and Holstein-Friesian newborn calves
}

\author{
Ayano SATO ${ }^{1)}$, Toshihide KATO ${ }^{1)}$ and Motoshi TAJIMA ${ }^{1) *}$ \\ ${ }^{1)}$ School of Veterinary Medicine, Rakuno Gakuen University, Ebetsu, Hokkaido 069-8501, Japan
}

J. Vet. Med. Sci.

83(6): 940-946, 2021

doi: 10.1292/jvms.20-0615

Received: 21 October 2020

Accepted: 12 April 2021

Advanced Epub:

30 April 2021

\begin{abstract}
Flexural and hyperextension deformities are congenital problems in calves. We, therefore, aimed to investigate the distal limb conformation in 1 day- and 28-day-old female Holstein-Friesian (HF) calves ( $n=21)$, male Japanese Black (JB) calves $(n=15)$, and female JB calves $(n=15)$. The claw angle of the forelimb dorsal claw wall in a standing position and recorded other parameters, including body weight, withers height, circumference of forelimbs, and flexor tendon thickness in the forelimbs, were measured and compared these between the three groups. At 1 day old, the mean claw angles were $51.1^{\circ}$ in female $\mathrm{HF}$ calves, $47.0^{\circ}$ in male JB calves, and $41.8^{\circ}$ in female JB calves; the $95 \%$ confidence intervals ( $\mathrm{Cls}$ ) of the claw angles showed large distributions in all three groups. One female HF and one male JB calves showed mild flexural deformity, whereas four JB calves showed hyperextension deformity. At 28 days old, the mean claw angles were $51.7^{\circ}$ in female HF calves, $51.2^{\circ}$ in male JB calves, and $48.4^{\circ}$ in female JB calves; the $95 \%$ Cls of the claw angles showed smaller distributions than those at 1 day old in all groups. For all groups, the limb deformities had improved without treatment at 28 days old. As a feature of the breed, female JB calves were apt to show hyperextended deformities inversely proportional to the body weight. These limb deformities healed spontaneously and were thought to be physiological.
\end{abstract}

KEY WORDS: breed, calf, conformation, forelimb

Musculoskeletal system diseases in cattle can result from congenital abnormalities or from acquired diseases [4]. In calves, congenital flexural or hyperextension deformities are presented as problems [4, 25]. Flexural deformity ranges in severity from mild knuckling at the fetlock to being unable to walk or stand. Similarly, the degree of hyperextension varies from weak flexors to walking on the palmar side of the fetlock joint. The etiology of congenital flexor or hyperextension deformities in calves is currently unknown. Numerous studies regarding limb conformation in adult cattle have been conducted and are used for breeding evaluation $[9,15,18,20]$. However, reports regarding limb conformation in calves, including limb deformity, are scarce [24].

In newborn foals, limb deformation, including flexural and hyperextension deformities, often occurs, and several studies have evaluated the changes in conformation during growth [2, 16,21]. Tendencies of limb deformation correlated with breed [21], and significant inter-breed differences in the distribution and severity of radiographic findings of the limb joints of foals at weaning have been recorded [10]. Such information could provide useful evidence for breeding and clinical treatment.

This study aimed to investigate the distal limb conformation at birth and 1 month of age in Holstein-Friesian (HF) and Japanese Black (JB) breeds. Because limb deformities in calves are more likely to occur in the distal forelimbs, we recorded the angle of the forelimb dorsal claw wall on the ground in a standing position in female HF and male and female JB calves. We measured on 1-day-old and 28-day-old calves and analyzed these measurements of the three groups for inter-group and intra-group variability. The correlation between the dorsal claw angle and other measurements, including body weight, withers height, circumference of forelimbs, and flexor tendon thickness in the forelimbs, was also investigated.

\section{MATERIALS AND METHODS}

\section{Animals}

This study was conducted following the guidelines of the Experimental Animal Research Committee of Rakuno Gakuen University. The trial was conducted between October 2017 and March 2019. Fifty-five neonatal calves (21 female HF, 15 male JB, and 19 female JB) born at the Field Educational Center affiliated to Rakuno Gakuen University were included. In this study, 55 calves were studied and divided into the following three groups: female HF, male JB, and female JB groups. 

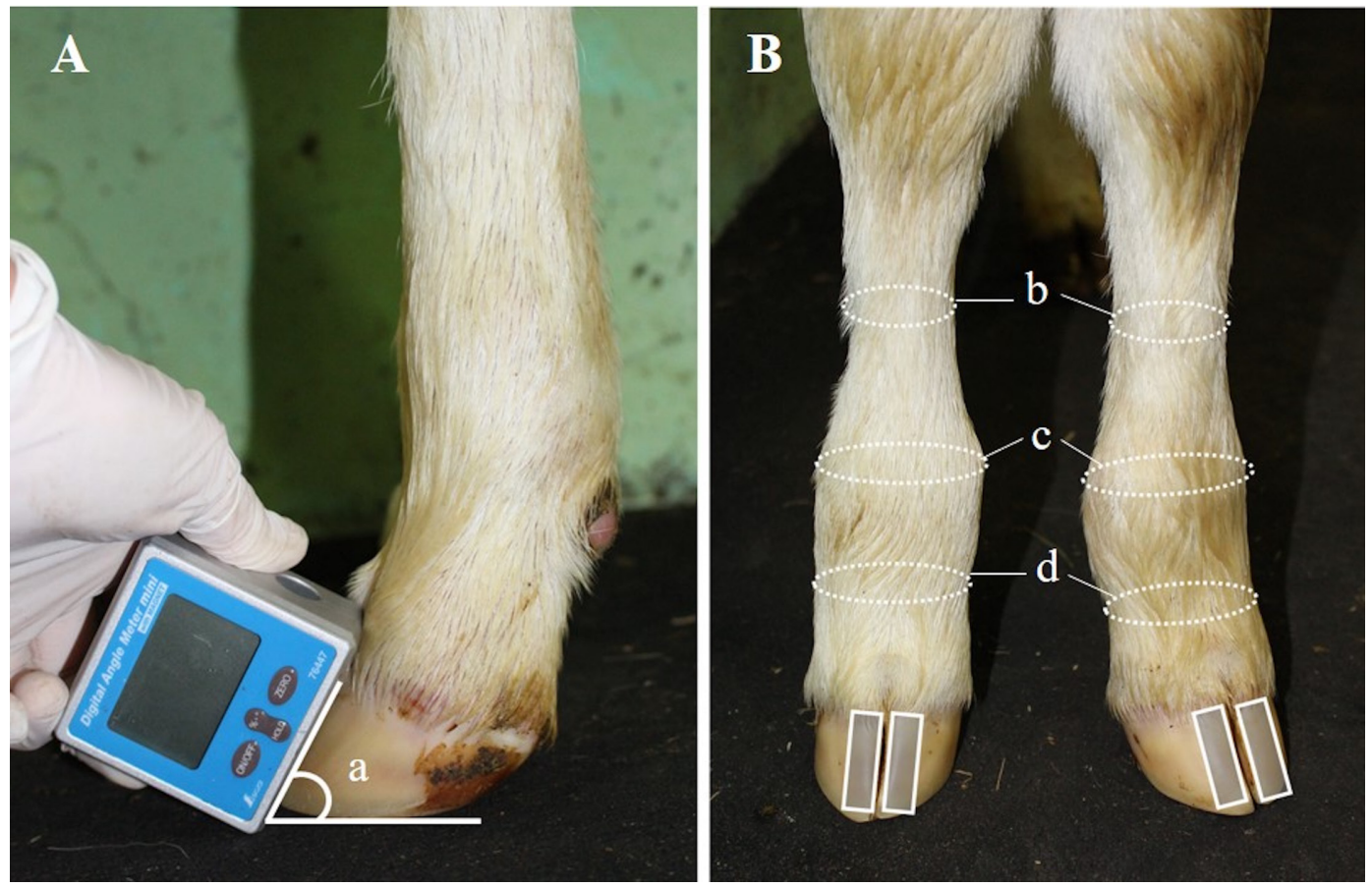

Fig. 1. Description of the measurement of the claw angle and circumference of forelimbs. (A) The claw angle was measured in the standing position with the forelimb using a digital angle meter from the left lateral side. (a) Lateral claw angle on the left forelimb. (B) The picture from the dorsal side. A digital angle meter (gray box) was placed on the axial claw wall of the medial and lateral claw on both forelimbs. The claw angle obtained from an individual animal was defined as the average value of the four measured regions. The circumference of the limbs was measured at three areas, indicated by the dotted lines: (b) cannon; thinnest part of the cannon, (c) fetlock joint; the thickest circumference of the fetlock joint above the dewclaw, (d) pastern; the thinnest part of the pastern below the dewclaw. Each circumference was defined as the average value of both forelimbs.

According to traditional JB cow rearing, JB calves stayed with dams after birth and took colostrum from the dam. HF calves were immediately separated from the dam after birth and were housed in individual pens; colostrum was taken using a feeding bottle within $24 \mathrm{hr}$ after birth. JB calves were separated from dams at 7 days old and moved into individual pens. JB calves were fed with milk replacement, which included $28 \%$ crude protein increasing from 800 to 1,400 g per feed twice a day for 8 to 28 days. HF calves were fed colostrum from the dam for the first 5 days and then fed with a milk replacement, which included $24 \%$ crude protein increasing from 800 to 1,400 g per feed twice a day for 6 to 28 days. All calves had access to hay, water, and calf meal. The calves were first examined at $24-48 \mathrm{hr}$ from birth ( 1 day old) and again at 28 days old.

\section{Physical examination}

In the standing position, the claw angle of the forelimbs, body weight, withers height, and circumference of both forelimbs were measured. The claw angle was defined as the angle of the anterior axial claw wall when standing on the concrete ground and measured by loading to the forelimb (Fig. 1). The claw angles of both forelimbs were measured at the medial and lateral claw of the axial wall using a digital angle meter (Digital Angle Meter mini, Shinwa, Niigata, Japan). The claw angle obtained from an individual animal was defined as the average value of the four measured regions. Body weight was measured using a weighing machine or weighing tape measure (FHK, Tokyo, Japan), and withers height was measured using a measuring stick (FHK). The circumference of the forelimbs was measured using a tape measure (Shinwa). Three areas of the forelimbs: cannon (thinnest part of the cannon), fetlock joint (the thickest circumference of the fetlock joint above the dewclaw), and pastern (the thinnest part of the pastern below the dewclaw) were measured (Fig. 1). For each individual animal, the measurements of circumference were defined as the average values of the left and right forelimbs. Therefore, the circumference values included the average measurements of the cannon, fetlock joint, and pastern of both forelimbs.

\section{Ultrasonographic examination}

For ultrasonographic examination, the calves were sedated using $2 \%$ xylazine ( $2 \%$ Seractal; Bayer, Osaka, Japan) by $0.2 \mathrm{mg} / \mathrm{kg}$ intravenous administration. The calves were laid on their left side, and the hair was clipped for examination. The ultrasonographic examinations were conducted according to the methods previously described $[7,8]$ using a portable diagnostic ultrasound imaging system (HS-1600V; Honda-Denshi, Toyohashi, Japan) with a linear probe (HLS-884M, frequency configured 8.5 MHz). The calves were inspected on the pattern of both forelimbs at the lateral and medial claws. Therefore, four ultrasonographic figures of the deep digital flexor tendon (DDFT) and superior digital flexor tendon (SDFT), marked by the distal annular digital ligament, were obtained for each calf (Fig. 2). 

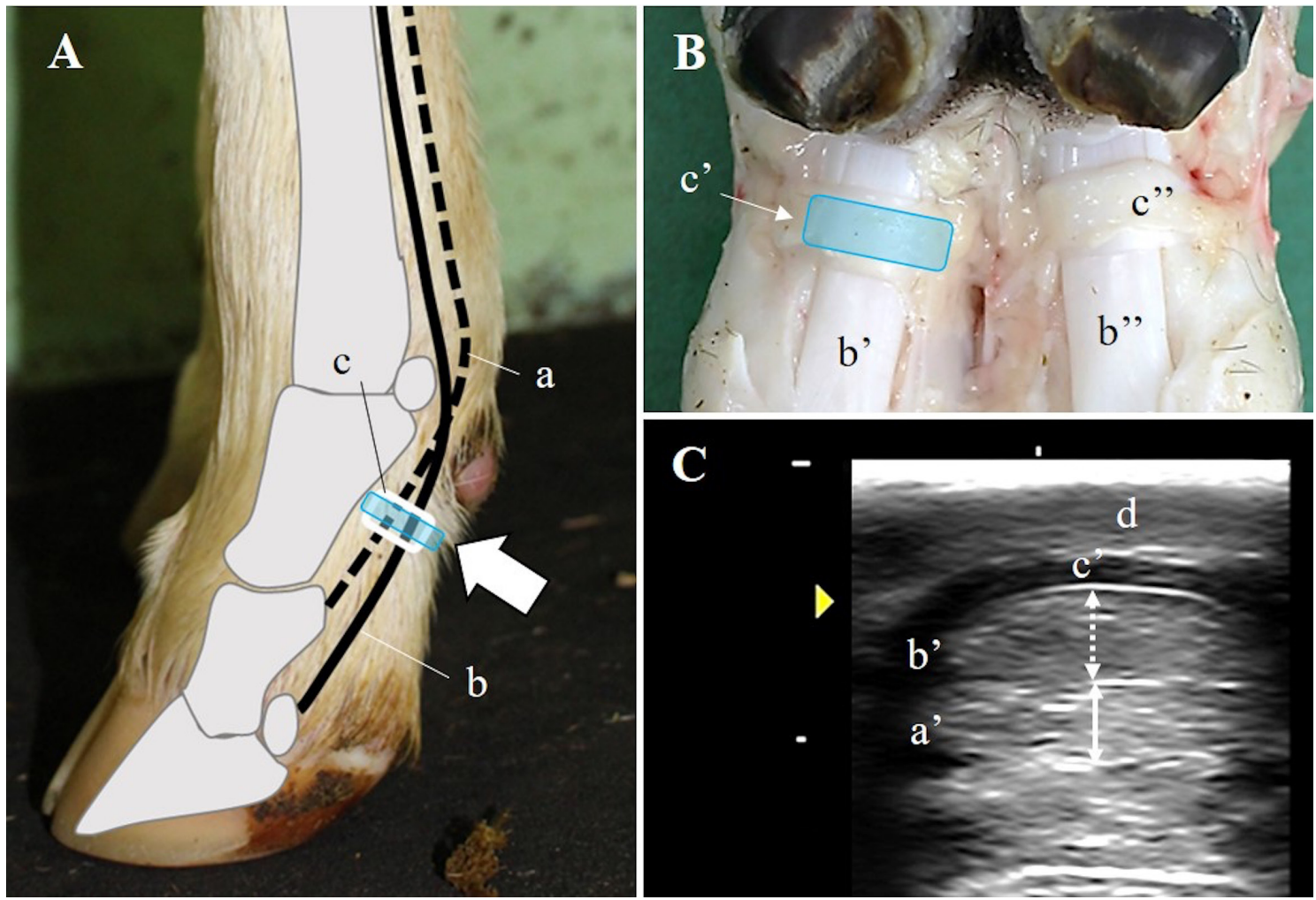

Fig. 2. Description of the ultrasound imaging method for flexor tendon thickness measurement. The probe region on the forelimb showed as the blue box. (A) The figure from the lateral. The probe was connected to the region indicated by the white arrow. (B) Photograph of the right forelimb on the palmar side of the measurement region where the skin was removed. The probe was connected to the medial side of the distal annular digital ligament (DACL). (C) Ultrasound image of flexor tendons obtained from the medial claw of the right forelimb. Deep digital flexor tendon (DDFT) thickness is represented by the length of the solid arrow, and the superior digital flexor tendon (SDFT) thickness is represented by the dotted arrow. a; SDFT, a'; medial side of SDFT, b; DDFT, b'; medial side of DDFT, b"; Lateral side of DDFT, c; DADL, c'; medial side of DADL, c"; lateral side of DADL, d; skin.

\section{Image analysis}

The ultrasonograms were saved as JPEG files and analyzed using image analysis software (ImageJ, v1.48, NIH, Bethesda, MD, USA). The maximum thickness in SDFT and DDFT was measured and indicated as millimeters ( $\mathrm{mm}$ ) in the pixel format using the scale on the ultrasonographic screen display (Fig. 2).

\section{Statistical analysis}

The comparisons between the first and second examinations between the three groups and the parameters were adjusted using the Bonferroni method after two-way ANOVA as a post hoc test. The correlations of the claw angle with the other measurements were analyzed using Pearson's correlation coefficient. All statistical analyses were conducted using SPSS Statistics (v.24, IBM, Armonk, NY, USA). Data were expressed as means and 95\% confidence intervals (CIs). For all comparisons, $P$-values of less than 0.05 were considered statistically significant.

\section{RESULTS}

\section{Measurement values and comparison of all measurements}

Table 1 shows the results of all measurements by sex and breed at 1-day-old and 28-day-old, and Table 2 shows the results of statistical analysis by sex and breed separately at 1-day-old and 28-day-old.

The mean claw angle at 1 day old was $51.1^{\circ}$ in female HF calves, $47.0^{\circ}$ in male JB calves, and $41.8^{\circ}$ in female JB calves. A female HF calf with a maximum claw angle of $76.0^{\circ}$ showed mild flexor deformities of the fetlock joint, and a female JB calf with a minimum value of $28.3^{\circ}$ showed mild hyperextended deformity. However, all calves could stand by themselves and could walk at 1-day-old. At 28-day-old, the mean claw angles were $51.7^{\circ}$ in female HF calves, $51.2^{\circ}$ in male JB calves, and $48.4^{\circ}$ in female JB calves. The maximum value was $61.5^{\circ}$ in a male JB calf, and the minimum value was $38.5^{\circ}$ in a female JB calf. The minimum value at 1-day-old and at 28-day-old showed in different calves. All calves showed normal gait and displayed no locomotor disease. At 1-day-old, the $95 \%$ CIs of the claw angle showed a large distribution in all three groups, and both flexor and hyperextended deformities were observed. However, at 28 -day-old, the $95 \%$ CIs in all groups showed a smaller distribution than those at 1 -day- 
Table 1. The mean and $95 \%$ confidence intervals in results of all measurements by sex and breed separately at 1-day-old and 28 -day-old

\begin{tabular}{|c|c|c|c|c|c|c|c|c|}
\hline & & & \multicolumn{3}{|c|}{1 day old } & \multicolumn{3}{|c|}{28 days old } \\
\hline & & & $\begin{array}{l}\text { Female HF } \\
\quad(\mathrm{n}=21)\end{array}$ & $\begin{array}{l}\text { Male JB } \\
(\mathrm{n}=15)\end{array}$ & $\begin{array}{l}\text { Female JB } \\
(\mathrm{n}=19)\end{array}$ & $\begin{array}{l}\text { Female HF } \\
(\mathrm{n}=21)\end{array}$ & $\begin{array}{l}\text { Male JB } \\
(\mathrm{n}=15)\end{array}$ & $\begin{array}{l}\text { Female JB } \\
(\mathrm{n}=19)\end{array}$ \\
\hline Claw angle & & $\left(^{\circ}\right)$ & $\begin{array}{c}51.1 \\
(34.2-68.1)\end{array}$ & $\begin{array}{c}47.0 \\
(27.6-66.3)\end{array}$ & $\begin{array}{c}41.8 \\
(24.5-59.2)\end{array}$ & $\begin{array}{c}51.7 \\
(44.0-59.3)\end{array}$ & $\begin{array}{c}51.2 \\
(42.7-59.7)\end{array}$ & $\begin{array}{c}48.4 \\
(38.5-58.2)\end{array}$ \\
\hline Body weight & & $(\mathrm{kg})$ & $\begin{array}{c}42.6 \\
(34.0-51.3)\end{array}$ & $\begin{array}{c}37.8 \\
(25.5-50.2)\end{array}$ & $\begin{array}{c}32.9 \\
(27.2-38.7)\end{array}$ & $\begin{array}{c}68.0 \\
(57.4-78.5)\end{array}$ & $\begin{array}{c}58.8 \\
(35.6-82.0)\end{array}$ & $\begin{array}{c}53.3 \\
(42.0-64.7)\end{array}$ \\
\hline Withers height & & $(\mathrm{cm})$ & $\begin{array}{c}79.9 \\
(74.3-85.5)\end{array}$ & $\begin{array}{c}74.9 \\
(67.2-82.3)\end{array}$ & $\begin{array}{c}71.4 \\
(65.8-77.0)\end{array}$ & $\begin{array}{c}88.0 \\
(82.9-93.1)\end{array}$ & $\begin{array}{c}79.5 \\
(72.6-86.3)\end{array}$ & $\begin{array}{c}76.2 \\
(70.9-81.6)\end{array}$ \\
\hline \multirow[t]{3}{*}{ Circumsference in forelimb } & Cannon & $(\mathrm{cm})$ & $\begin{array}{c}105.5 \\
(99.9-111.1)\end{array}$ & $\begin{array}{c}110.3 \\
(98.3-122.3)\end{array}$ & $\begin{array}{c}103.2 \\
(93.4-112.9)\end{array}$ & $\begin{array}{c}110.9 \\
(104.2-117.5)\end{array}$ & $\begin{array}{c}118.3 \\
(105.1-131.4)\end{array}$ & $\begin{array}{c}111.2 \\
(100.4-122.0)\end{array}$ \\
\hline & Fetlock & $(\mathrm{cm})$ & $\begin{array}{c}175.2 \\
(162.7-187.6)\end{array}$ & $\begin{array}{c}179.2 \\
(158.5-199.9)\end{array}$ & $\begin{array}{c}166.1 \\
(148.0-184.2)\end{array}$ & $\begin{array}{c}186.5 \\
(176.4-196.6)\end{array}$ & $\begin{array}{c}191.5 \\
(168.8-214.1)\end{array}$ & $\begin{array}{c}178.7 \\
(163.3-194.2)\end{array}$ \\
\hline & Pastern & $(\mathrm{cm})$ & $\begin{array}{c}149.6 \\
(141.2-158.0)\end{array}$ & $\begin{array}{c}159 \\
(144.7-173.3)\end{array}$ & $\begin{array}{c}149.8 \\
(137.5-162.1)\end{array}$ & $\begin{array}{c}159.5 \\
(150.7-168.3)\end{array}$ & $\begin{array}{c}168.1 \\
(146.7-189.6)\end{array}$ & $\begin{array}{c}158.5 \\
(144.8-172.2)\end{array}$ \\
\hline \multirow[t]{4}{*}{$\begin{array}{l}\text { Thickness of flexor tendon } \\
\text { in forelimb }\end{array}$} & $\begin{array}{l}\text { Lateral } \\
\text { DDFT }\end{array}$ & $(\mathrm{cm})$ & $2.3(1.8-2.7)$ & $2.4(1.8-3.0)$ & $2.4(1.8-2.9)$ & $2.7(2.2-3.3)$ & $2.9(2.2-3.6)$ & $2.7(2.2-3.3)$ \\
\hline & $\begin{array}{l}\text { Medial } \\
\text { DDFT }\end{array}$ & $(\mathrm{cm})$ & $2.4(1.9-3.0)$ & $2.5(1.8-3.2)$ & $2.5(1.9-3.0)$ & $2.9(2.4-3.5)$ & $3.1(2.3-3.9)$ & $2.9(2.1-3.5)$ \\
\hline & $\begin{array}{l}\text { Lateral } \\
\text { SDFT }\end{array}$ & $(\mathrm{cm})$ & $1.5(1.1-1.9)$ & $1.5(1.1-1.9)$ & $1.5(1.1-1.8)$ & $1.5(1.1-2.0)$ & $1.6(1.0-2.1)$ & $1.6(1.1-2.1)$ \\
\hline & $\begin{array}{l}\text { Medial } \\
\text { SDFT }\end{array}$ & $(\mathrm{cm})$ & $1.5(1.1-1.8)$ & $1.5(1.1-2.0)$ & $1.4(1.1-1.8)$ & $1.5(1.0-1.9)$ & $1.6(1.0-2.1)$ & $1.5(1.0-2.1)$ \\
\hline
\end{tabular}

HF, Holstein-Friesian; JB, Japanese Black; CI, confidence intervals; DDFT, deep digital flexor tendons; SDFT, superior digital flexor tendons.

Table 2. Measurement of results in statistical analysis by sex and breed separately at 1-day-old and 28-day-old

\begin{tabular}{|c|c|c|c|c|c|c|c|c|}
\hline & & & & wo-way ANC & & & Bonferroni & \\
\hline & & & & $P$ value & & & $P$ value $(95 \% \mathrm{CI})$ & \\
\hline & & & Interaction & $\begin{array}{l}\text { Variation } \\
\text { between } \\
\text { subgroups }\end{array}$ & $\begin{array}{l}\text { Variation } \\
\text { within a } \\
\text { subgroup }\end{array}$ & $\begin{array}{l}\text { Between female HF } \\
\text { and male JB }\end{array}$ & $\begin{array}{l}\text { Between female HF } \\
\text { and female JB }\end{array}$ & $\begin{array}{c}\text { Between male JB and } \\
\text { female JB }\end{array}$ \\
\hline Claw angle & & $\left({ }^{\circ}\right)$ & 0.161 & $<0.001 * *$ & $0.006^{* *}$ & $\begin{array}{c}0.494 \\
(-6.404-1.728)\end{array}$ & $\begin{array}{c}<0.001 * * \\
(2.488-10.105)\end{array}$ & $\begin{array}{c}0.067 \\
(-0.196-8.114)\end{array}$ \\
\hline Body weight & & $(\mathrm{kg})$ & 0.179 & $<0.001 * *$ & $<0.001 * *$ & $\begin{array}{c}<0.001^{* *} \\
(3.279-10.710)\end{array}$ & $\begin{array}{c}<0.001 * * \\
(8.707-15.667)\end{array}$ & $\begin{array}{c}0.004^{* *} \\
(1.396-8.989)\end{array}$ \\
\hline Withers height & & $(\mathrm{cm})$ & $0.024 *$ & $<0.001 * *$ & $<0.001 * *$ & - & - & - \\
\hline $\begin{array}{l}\text { Circumsference } \\
\text { in forelimb }\end{array}$ & Cannon & $(\mathrm{cm})$ & 0.362 & $<0.001 * *$ & $<0.001^{* *}$ & $\begin{array}{c}<0.001 * * \\
(3.355-8.854)\end{array}$ & $\begin{array}{c}1.000 \\
(-3.569-1.581)\end{array}$ & $\begin{array}{c}<0.001 * * \\
(4.290-9.908)\end{array}$ \\
\hline & Fetlock & $(\mathrm{cm})$ & 0.938 & $<0.001 * *$ & $<0.001 * *$ & $\begin{array}{c}0.072 \\
(-0.283-9.283)\end{array}$ & $\begin{array}{c}<0.001^{* *} \\
(3.920-12.878)\end{array}$ & $\begin{array}{c}<0.001^{* *} \\
(8.013-17.785)\end{array}$ \\
\hline & Pastern & $(\mathrm{cm})$ & 0.918 & $<0.001^{* *}$ & $<0.001 * *$ & $\begin{array}{c}<0.001^{* *} \\
(5.191-12.833)\end{array}$ & $\begin{array}{c}1.000 \\
(-4.005-3.152)\end{array}$ & $\begin{array}{c}<0.001^{* *} \\
(5.535-13.343)\end{array}$ \\
\hline $\begin{array}{l}\text { Thickness of } \\
\text { flexor tendon }\end{array}$ & $\begin{array}{l}\text { Lateral } \\
\text { DDFT }\end{array}$ & $(\mathrm{cm})$ & 0.684 & $0.022 *$ & $<0.001^{* *}$ & $\begin{array}{c}0.021^{*} \\
(0.019-0.308)\end{array}$ & $\begin{array}{c}1.000 \\
(-0.099-0.172)\end{array}$ & $\begin{array}{c}0.118 \\
(-0.021-0.274)\end{array}$ \\
\hline in forelimb & $\begin{array}{l}\text { Medial } \\
\text { DDFT }\end{array}$ & $(\mathrm{cm})$ & 0.378 & $0.033^{*}$ & $<0.001^{* *}$ & $\begin{array}{c}0.103 \\
(-0.020-0.317)\end{array}$ & $\begin{array}{c}1.000 \\
(-0.187-0.130)\end{array}$ & $\begin{array}{c}0.042 * \\
(0.005-0.350)\end{array}$ \\
\hline & $\begin{array}{l}\text { Lateral } \\
\text { SDFT }\end{array}$ & $(\mathrm{cm})$ & 0.868 & 0.746 & 0.091 & $\begin{array}{c}1.000 \\
(-0.144-0.078)\end{array}$ & $\begin{array}{c}1.000 \\
(-0.081-0.127)\end{array}$ & $\begin{array}{c}1.000 \\
(-0.103-0.123)\end{array}$ \\
\hline & $\begin{array}{l}\text { Medial } \\
\text { SDFT }\end{array}$ & $(\mathrm{cm})$ & 0.362 & 0.171 & 0.326 & $\begin{array}{c}0.189 \\
(-0.193-0.025)\end{array}$ & $\begin{array}{c}1.000 \\
(-0.128-0.076)\end{array}$ & $\begin{array}{c}0.612 \\
(-0.053-0.170)\end{array}$ \\
\hline
\end{tabular}

HF, Holstein-Friesian; JB, Japanese Black; CI, confidence intervals; DDFT, deep digital flexor tendons; SDFT, superior digital flexor tendons. $* P<0.05 ; * * P<0.01$.

old, and the calves that had shown deformities at birth had improved spontaneously without treatment. For the claw angle, a significant interaction effect was not observed $(P=0.161)$, and the claw angle in female JB calves was significantly lower than that in female HF calves (95\% CI: 2.488-10.105, $P<0.001$; Table 2).

There was no significant interaction effect for body weight $(P=0.179)$, and increases in body weight were seen at 28 -day-old compared to 1-day-old $(P<0.001)$, with female HF calves being heavier than male JB calves and male JB calves being heavier than female JB calves (female HF vs. male JB, 95\% CI: 3.279-10.710, $P<0.001$; female HF vs. female JB, 95\% CI: 8.707-15.667, $P<0.001$; male JB vs. female JB, 95\% CI: $1.396-8.989, P=0.004)$. A significant interaction effect was observed for withers height $(P=0.02)$ : at 
1-day-old, withers height was higher in the order of female HF calves, male JB calves, and female JB calves (female HF vs. male JB, 95\% CI: $2.528-7.815, P<0.001$; male JB vs. female JB, 95\% CI: $0.664-6.066, P<0.010$; female HF vs. female JB, 95\% CI: $6.060-11.013, P<0.001)$. Similar to the results at 1-day-old withers height was also higher in the order of female HF calves, male JB calves, and female JB calves (female HF vs. male JB, 95\% CI: 6.129-10.985, $P<0.001$; male JB vs. female JB, 95\% CI: 0.749-5.711, $P=0.007$; female HF vs. female JB, 95\% CI: 9.513-14.061, $P<0.001)$ at 28 -day-old. Both body weight and withers height were greater in the order of female HF calves, male JB calves, and female JB calves.

For the circumference of the limbs, there were no significant interactions at all three parts of the limbs, and the limbs were thicker at 28-day-old than those at 1-day-old (Table 2). Male JB calves had thicker limbs than the other two groups according to the circumference of the cannons (male JB vs. female HF, 95\% CI: $3.355-8.854, P<0.001$; male JB vs. female JB, $95 \% \mathrm{CI}$ : 4.290-9.908, $P<0.001$ ) and pasterns (male JB vs. female HF, 95\% CI: 5.191-12.833, $P<0.001$; male JB vs. female JB, 95\% CI: 5.535-13.343, $P<0.001$ ), and female JB had thinner limbs than the other two groups according to the fetlock measurements (female JB vs. female HF, 95\% CI: 3.920-12.878, $P<0.001$; female JB vs. male JB, $95 \%$ CI: 8.013-17.785, $P<0.001)$. Male JB calves had thicker limbs than calves in the other two groups according to the cannon and pastern measurements. For fetlocks, female JB calves had thinner limbs than those of the other two groups.

There were no significant interactions for either SDFT or DDFT (Table 2). It was shown that the DDFT at 28-day-old was significantly thicker than that at 1 -day-old (both lateral and medial claw; $P<0.001$ ). Furthermore, DDFT in the lateral claw of male JB calves was significantly thicker than that of female HF calves (95\% CI: $0.019-0.308, P=0.021)$, and the DDFT in the medial claw of male JB calves was significantly thicker than that of female JB calves $(95 \% \mathrm{CI}: 0.005-0.350, P=0.041)$. DDFT in male JB calves thickened with growth and was more distinct in this group than in the other groups. However, the thickness of SDFT did not show any significant differences.

\section{Correlation between claw angle and other measurements}

We investigated the correlations between claw angle and body weight, withers height, circumference of forelimbs, and flexor tendon thickness in forelimbs separately for the three groups. A significant positive correlation coefficient of $\mathrm{R}=0.714(P<0.001)$ between claw angle and body weight was observed in female JB calves at 1-day-old (Fig. 3). However, the correlation coefficient between claw angle and body weight in female JB calves at 28 days old was $\mathrm{R}=0.158(P=0.518)$, indicating no correlation. The correlation between claw angle and body weight of female HF calves and male JB calves was not significant. Correlation coefficients less than -0.7 or higher than 0.7 were not found for the other measurements.

\section{DISCUSSION}

In the present study, distal limb conformation was investigated using the measurements of claw angles and limb support tissues in forelimbs in HF and JB calves at 1-day-old and 28-day-old. Immediately after birth, the claw angles varied among individuals, including flexed and hyperextended limbs, regardless of breed, but in all three groups, calves had improved without treatment after 28 days. There was a tendency for immaturity in JB calves compared to HF calves for body weight and limb support tissues, especially female JB calves, who were apt to show hyperextended deformities in an inverse ratio to their body weight. It was thought that body weight and withers height may be affected by differences in breed and sex. Male JB calves were born with and grew thicker limbs compared to the other groups and had a more apparent concomitant increase in DDFT thickness. The results of the present study indicate that the claw angle of calves immediately after birth varies greatly among individuals. Even calves that showed mild flexural and hyperextended deformities healed spontaneously, regardless of breed and sex, if they could stand and walk.

Blood components at and after birth differ between HF and JB calves [17, 22]. Reportedly, colostrum composition differs between breeds, as well as calf immunity and growth rate. Several studies have evaluated limb conformation in adult cows as a genetic assessment, along with hoof disease assessment $[9,15,18,20]$. However, reports on limb conformation in newborn calves, including breed-specific differences, are limited. In the present study, between- and within-group comparisons of changes from 1-day-old to 28-day-old in physique and forelimbs were investigated in female HF calves, male JB calves, and female JB calves. The average claw angle in female HF calves was $51^{\circ}$ at both 1-day-old and 28-day-old, and they were born bigger and maintained their size with growth compared to male JB calves. The ideal claw toe angle of an adult dairy cow has been reported to 
be approximately $50^{\circ}[3,13,14]$. The real toe angles of the claws were not measured in this study. However, because calves with a claw angle close to $51^{\circ}$ when stood with the entire sole, $51^{\circ}$ was considered a physiological toe claw angle for calves. In female HF calves, claw angle correlated with an increase in withers height growth, and it also correlated with slimmer forelimb thickness and DDFT thickness in male JB calves. Therefore, female HF calves were born in mature state and grew slimmer than male JB calves. Most female HF calves showed normal limb conformation after birth, with only one calf exhibiting mild flexor deformities. The calf showed over $70^{\circ}$ on claw angle and did not touch the heel on the ground.

JB calves are genetically characterized by their smaller body size and extremely lightweight at birth compared with other breeds [6]. In this study, we found that male JB calves were smaller than female HF calves in body weight and withers height, but they grew with thicker limbs and thicker DDFT. Male JB calves were more likely to present with hyperextended deformities than flexural deformities, probably because of their low birth weight, but showed normal limbs at 28-day-old without treatment. Female JB calves were the smallest of the three groups in terms of body weight and withers height. Because of the average claw angle at 1-day-old $\left(42^{\circ}\right)$, no female JB calves had flexural deformities, but the number of calves showing hyperextended deformities was the highest among the three groups. Even at 28-day-old, the average claw angle was $48^{\circ}$, which was small at 1 month of age, and the limb and DDFT thicknesses were also thinner than those of male JB calves. From the results of this study, it was suggested that newborn JB calves showed not only light body weight but also immature limb support structures. Especially in female JB calves, immature limb support structures showed not only at 1-day-old but also at 28-day-old. In male JB calves at 1-day-old, it was thought that light body weight caused immature and unbalanced in limb support. Consequently, one male JB calf showed hyperextended deformities despite thick DDFT. The calf showed under $30^{\circ}$ on claw angle and did not touch the toe on the ground. In palpation, the distal limb joint gives the impression of loose soft tissue around the joint rather than being pulled by the extensor tendons. With weight gain and exercise load on the limb, it was thought that the DDFT developed to function at 28-day-old due to the development of the support function of the limb.

Neonatal foals show various limb deformities, including carpal valgus, fetlock valgus, over-at-the-knee, dropped fetlocks, club feet, and fetlock varus [21]. A high percentage of newborn foals with limb deformities immediately after birth have been reported, but most foals have healed spontaneously by the time they are weaned $[2,11,16,23]$. In newborn calves, limb deformities are most commonly caused by flexor deformities in the fetlock joint $[1,19,25]$. Most limb deformities with palmar/dorsal flexion or dorsal hyperextension are mild and have a good prognosis $[4,5,12]$. One female HF and one male JB calves in the present study showed flexor deformities in the fetlock joint, but all calves had mild symptoms that resolved spontaneously. One male JB calf showed forelimb flexor deformities of the carpus joint, which improved without treatment by 28 days of age. In foals, there are significant limb conformational differences between the breeds, especially in the first months of life [21]. In the present study, we compared HF calves and JB calves and found that JB calves were more likely to exhibit hyperextended deformities. The results suggest that understanding the peculiarities of specific breeds may be useful for evaluating individual calf conformation.

To conclude, limb conformation in newborn calves was shown in some limb deformities, such as mildly hyperextended and flexor deformities, regardless of breed, and a tendency of hyperextended deformities in low-weight JB calves was observed as a characteristic of the breed. However, these limb deformities healed spontaneously and were believed to be physiological. This work will contribute to the evidence of the breed characteristics of calves.

POTENTIAL CONFLICTS OF INTEREST. The authors have nothing to disclose.

ACKNOWLEDGMENTS. The authors would like to acknowledge the support of the farmers and staff in the Field Educational Center affiliated with Rakuno Gakuen University. The technical support input of Dr. O Dochi, K Imai, T Nishisozu and T Inamori, Rakuno Gakuen University, JP are also acknowledged.

\section{REFERENCES}

1. Anderson, D. E., Desrochers, A. and St Jean, G. 2008. Management of tendon disorders in cattle. Vet. Clin. North Am. Food Anim. Pract. 24: 551-566, viii. [Medline] [CrossRef]

2. Anderson, T. M. and McIlwraith, C. W. 2004. Longitudinal development of equine conformation from weanling to age 3 years in the Thoroughbred. Equine Vet. J. 36: 563-570. [Medline] [CrossRef]

3. Archer, S. C., Newsome, R., Dibble, H., Sturrock, C. J., Chagunda, M. G. G., Mason, C. S. and Huxley, J. N. 2015. Claw length recommendations for dairy cow foot trimming. Vet. Rec. 177: 222. [Medline] [CrossRef]

4. Ducharme, N. G., Desrochers, A. and Freeman, D. 2017. Surgery of flexural and hyperextension deformities. pp. 519-523. In: Farm Animal Surgery, 2nd ed. (Fubini, S. L. and Ducharme, N. G. eds.), Elsevier, St. Louis.

5. Fazili, M. R., Bhattacharyya, H. K., Mir, M., Hafiz, A. and Tufani, N. A. 2014. Prevalence and effect of oxytetracycline on congenital fetlock knuckling in neonatal dairy calves. Onderstepoort J. Vet. Res. 81: 1-6. [Medline] [CrossRef]

6. Fukuhara, R. 1988. Life and development of beef cattle. pp. 37-58. In: Agricultural Technique System: Livestock volume, NosangyosonbunkaKyokai, Tokyo.

7. Gonçalves, P. V. R., Silva, L. A. F., Silva, L. H., Costa, A. P. A., Bragato, N., Cardoso, J. R., Kofler, J. and Borges, N. C. 2014. Ultrasonography of the distal limbs in Nellore and Girolando calves 8 to 12 months of age. BMC Vet. Res. 10: 102. [Medline] [CrossRef]

8. Kofler, J. and Edinger, J. K. 1995. Diagnostic ultrasound imaging of soft tissues in the bovine distal limb. Vet. Radiol. Ultrasound 36: $246-252$. [CrossRef]

9. Laursen, M. V., Boelling, D. and Mark, T. 2009. Genetic parameters for claw and leg health, foot and leg conformation, and locomotion in Danish Holsteins. J. Dairy Sci. 92: 1770-1777. [Medline] [CrossRef] 
10. Lepeule, J., Bareille, N., Valette, J. P., Seegers, H., Jacquet, S., Denoix, J. M. and Robert, C. 2008. Developmental orthopaedic disease in limbs of foals: between-breed variations in the prevalence, location and severity at weaning. Animal 2: 284-291. [Medline] [CrossRef]

11. Love, S., Wyse, C. A., Stirk, A. J., Stear, M. J., Calver, P., Voute, L. C. and Mellor, D. J. 2006. Prevalence, heritability and significance of musculoskeletal conformational traits in Thoroughbred yearlings. Equine Vet. J. 38: 597-603. [Medline] [CrossRef]

12. Metzner, M., Baumgart, I. and Klee, W. 2007. Effect of infusion of $60 \mathrm{mg} / \mathrm{kg}$ oxytetracycline on forelimb flexor tendon contracture in calves. Vet. Rec. 160: 166-167. [Medline] [CrossRef]

13. Nuss, K. and Paulus, N. 2006. Measurements of claw dimensions in cows before and after functional trimming: a post-mortem study. Vet. J. 172: 284-292. [Medline] [CrossRef]

14. Nuss, K., Sauter-Louis, C. and Sigmund, B. 2011. Measurements of forelimb claw dimensions in cows using a standardised sole thickness: a postmortem study. Vet. J. 190: 84-89. [Medline] [CrossRef]

15. Ødegård, C., Svendsen, M. and Heringstad, B. 2015. Foot and leg conformation traits have a small effect on genomic predictions of claw disorders in Norwegian Red cows. J. Dairy Sci. 98: 4139-4147. [Medline] [CrossRef]

16. O'Donohue, D. D., Smith, F. H. and Strickland, K. L. 1992. The incidence of abnormal limb development in the Irish thoroughbred from birth to 18 months. Equine Vet. J. 24: 305-309. [Medline] [CrossRef]

17. Ohtsuka, H., Komatsu, S., Konnai, S., Fukuda, S., Kiku, Y., Yoshino, T., Koiwa, M. and Kawamura, S. 2002. Comparison of peripheral leukocytes in Japanese black and Holstein calves. Nippon Juishikai Zasshi 73: 140-145.

18. Onyiro, O. M., Andrews, L. J. and Brotherstone, S. 2008. Genetic parameters for digital dermatitis and correlations with locomotion, production, fertility traits, and longevity in Holstein-Friesian dairy cows. J. Dairy Sci. 91: 4037-4046. [Medline] [CrossRef]

19. Pentecost, R., Niehaus, A. J. and Anderson, D. E. 2016. Surgical management of fractures and tendons. Vet. Clin. North Am. Food Anim. Pract. 32: 797-811. [Medline] [CrossRef]

20. Ring, S. C., Twomey, A. J., Byrne, N., Kelleher, M. M., Pabiou, T., Doherty, M. L. and Berry, D. P. 2018. Genetic selection for hoof health traits and cow mobility scores can accelerate the rate of genetic gain in producer-scored lameness in dairy cows. J. Dairy Sci. 101: 10034-10047. [Medline] [CrossRef]

21. Robert, C., Valette, J. P. and Denoix, J. M. 2013. Longitudinal development of equine forelimb conformation from birth to weaning in three different horse breeds. Vet. J. 198 Suppl 1: e75-e80. [Medline] [CrossRef]

22. Sano, K. 2009. Physiological feature of newborn calves in Holstein and Japanese Black. pp. 85-91. In: The Calf: Management from the Birth to First Childbirth (Ogata, Y., Okamoto, Z., Kimura, N., Koiwa, M. and Tsumagari, S. eds.), Midorishobo, Tokyo.

23. Santschi, E. M., Leibsle, S. R., Morehead, J. P., Prichard, M. A., Clayton, M. K. and Keuler, N. S. 2006. Carpal and fetlock conformation of the juvenile Thoroughbred from birth to yearling auction age. Equine Vet. J. 38: 604-609. [Medline] [CrossRef]

24. Sato, A., Ishii, O. and Tajima, M. 2018. Radiographic analysis of the angle in the lateromedial projection of the metacarpophalangeal joint and the distal interphalangeal joint in metacarpophalangeal flexural deformities in calves. Vet. Rec. Open 5: e000271. [Medline] [CrossRef]

25. Steiner, A., Anderson, D. E. and Desrochers, A. 2014. Diseases of the tendons and tendon sheaths. Vet. Clin. North Am. Food Anim. Pract. 30: 157-175, vi. [Medline] [CrossRef] 